\title{
Lapsevanemate hinnangud juhendamisstrateegiatele puutetundliku ekraani kasutamisel väikelapseeas
}

\author{
Elyna Nevskia ${ }^{a}$, Kristi Vinter ${ }^{\mathrm{a}}$ \\ a Tallinna Ülikooli haridusteaduste instituut
}

\begin{abstract}
Annotatsioon
Väikelaste kokkupuude puutetundlike ekraanidega algab juba imikueas ning esimese eluaasta jooksul saavad lastest regulaarsed meediatarbijad. Paraku ei ole ühest vastust, mil määral väikelapsed on suutelised puutetundliku ekraani vahendusel óppima ning kui palju nad vajavad selleks lapsevanema kaasabi. Kuna laste tehnoloogiakasutus on mõjutatud lapsevanemate uskumustest, on nende uurimine oluline. Uurimuse eesmärk on välja selgitada Eesti lapsevanemate arvamused puutetundlike seadmete kasutamise vajalikkuse kohta ning nende hinnangud juhendamisstrateegiatele nutiseadme kasutamisel väikelapseeas. Uuringust, milles osales 400 lapsevanemat, kellel on laps(i) vanuses 0-36 kuud, selgub, et peredes, kus vanemad seavad laste nutiseadmete kasutamisele nii aja- kui ka sisupiiranguid, kasutavad lapsed nutiseadmeid sagedamini kui peredes, kus piiranguid ei seata. Lapsevanemad näevad nutiseadme kasutamise eelisena seda, et laps õpib uusi oskusi, saab uusi teadmisi ning seade pakub lapsele meelelahutust. Nutiseadme võimaldamise peamine põhjus on vanemate võimalus teha samal ajal oma asjatoimetusi. 0-3aastaste laste vanemate seas pole aga välja kujunenud selgeid ja konkreetseid juhendamisstrateegiaid, pigem kasutavad vanemad nii aktiivse kui ka keelava juhendamise elemente korraga ja omavahel seotult. Tulemustest ilmneb, et puutetundliku ekraani kasutamise sagedus suureneb lapse vanuse kasvades. Samas ei mõjuta lapsevanemate haridustase nutiseadme kasutamise sagedust ega vanemlikke juhendamisstrateegiaid.
\end{abstract}

Võtmesõnad: väikelaps, videodefitsiit, puutetundlikud ekraanid, juhendamisstrateegiad

1 Haridusteaduste instituut, Tallinna Ülikool, Narva mnt 25, 10120 Tallinn; elyna.nevski@tlu.ee 


\section{Sissejuhatus}

Puutetundlikud ekraanid (ka nutiseadmed) on saanud meie igapäevakeskkonnas tavapäraseks kaaslaseks ning on kujunemas väikelaste kasvukeskkonna paratamatuks osaks (TNS Emor, 2014). Lapsevanematega tehtud uuringud (Holloway, Green, \& Livingstone, 2013; Rideout \& Hamel, 2006; Suoninen, 2013) näitavad, et väikelaste kontakt ekraanimeediaga algab juba kolmekuuselt ning esimese eluaasta jooksul saavad lastest regulaarsed meediatarbijad, kes kasutavad neile suunatud meediasisu päevas 1-2 tundi. Üks põhjuseid on meediatööstuse selge sõnum vanematele, et väikelastele suunatud meedia võimaldab lastel juba varakult õppida. Keel, kujundid, värvid, muusika, tähed ja numbrid, mis on põimitud huvitavasse ja pilkupüüdvasse videoformaati, on tootjate põhiline viis näidata lapsevanematele, et tegemist on hariva sisuga, mida väikelapsed võiksid juba maast madalast óppimise eesmärgil tarbida (Courage \& Howe, 2010).

Meediatootjate optimismist hoolimata on teadlased juba üle kümne aasta arutlenud selle üle, kas ekraanide kasutamine õppimise eesmärgil on laste jaoks kahjulik või kasulik, ilma et oleks jõutud ühisele seisukohale. Laste õppimist ekraani vahendusel on seostatud ühelt poolt sellega, et lapsevanemad toetavad aktiivselt väikest last puutetundliku ekraani kasutamisel (Sims \& Colunga, 2013), teisalt aga väikelaste ja imikute vähese ekraanilt õppimise võimega, mida mõjutab ekraani tajumise, sümbolite ja ekraanilt nähtud informatsiooni vähene mõistmine (Richert, Robb, \& Smith, 2011; Zack, Barr, Gerhardstein, Dickerson, \& Meltzoff, 2009). Mitmed uurijad (Barr, 2013; Zack et al., 2009) toovad välja, et väikelastel on keeruline ekraani sümbolilist maailma päriselu situatsioonidesse üle kanda ning uute teadmiste omandamine on silmast silma interaktsioonidest seetõttu ebatõhusam.

Kuna Eesti lapsevanemad soosivad digitaaltehnoloogiliste vahendite kasutamist eelkooliealiste laste hulgas, rõhutades selle arendavat mõju (Vinter, 2013), ning imikute ja väikelastega seotud uuringuid seni Eestis tehtud ei ole, on lapsevanemate arvamuse uurimine oluline. Liiati on laste tehnoloogiakasutus mõjutatud lapsevanemate uskumustest (Vinter, 2013), mistõttu annavad uurimistulemused hea lähtekoha lapsevanemate arusaamade kujundamiseks.

Eelnevast lähtudes püstitati uurimuse eesmärgiks välja selgitada, kuidas hindavad Eesti lapsevanemad puutetundlike seadmete kasutamise vajalikkust ja mõju lapse arengule ning mis strateegiaid rakendavad nad väikelapse juhendamiseks nutiseadme kasutamisel. 


\section{Väikelaps puutetundliku ekraani kasutajana}

Esimesed eluaastad (0-3) on lapse arengus väga olulised, sest sel ajal toimuvad suured muutused (areneb aju, kujunevad kognitiivsed ja füüsilised võimed ning sotsiaalsed oskused). Seetõttu tuleks juba lapse varases arengustaadiumis jälgida laste meediamustreid, mis võimaldaks teha hilisemaid järeldusi nende akadeemiliste võimete, kognitiivsete ja sotsiaalsete oskuste kohta (Cardany, 2010). Tähelepanu tuleb pöörata ohule, et meediatarbimisega võib kaasneda lapse aju ülestimuleerimine, sest kiirete kaadrivahetuste, lõikamiste ja suumimisvõtete tõttu võivad lapsed oodata samasugust stimulatsiooni ka päris elus (Christakis, 2009). Kuigi elemente, mis köidavad nii väikelaste kui ka vanemate laste tähelepanu ekraanil, peetakse sarnasteks, on laste meediaharjumused siiski erinevad, mistõttu väärivad alla kolmeaastased väikelapsed eraldi uurimist (Schmitt, Anderson, \& Collins, 1999). Alust uuringuteks annab asjaolu, et lastel on juba sündides olemas võimsad õppimismehhanismid, mis võimaldavad neil konstrueerida uusi pilte maailma kohta (Gopnik, Meltzoff, \& Kuhl, 2003). Samuti on lapsed aktiivsed õppijad, kes suudavad püstitada eesmärke, planeerida, tegevusi korrata, informatsiooni koguda ja seda korrastada (Bransford, Brown, \& Cocking, 2000). Meedia paneb lapsed küll tardunud pilguga ekraani vaatama, kuid ei ole selge, mida see tegelikult tähendab. Sellest võib järeldada, et laps naudib meedia vahendatud kogemust, aga see võib tähendada hoopis midagi muud (Cardany, 2010).

Ekraanimeedia hulka arvatakse peale televiisori ka mitmed muud ekraanid, millest traditsioonilise arvuti kõrvale on alates 2007. aastast tarbijaturule ilmunud nutitelefonid ja tahvelarvutid. Koos arvutiga on ekraanist väga kiiresti saanud üks peamine vahend, mis tagab ligipääsu igat tüüpi informatsioonile. Võib öelda, et elame ekraaniühiskonnas, sest ekraani kasutuselevõtt on koondanud eri tegevused ja informatsiooni ühte kohta - ekraanile (Manovich, 2012).

Ameerika lastearstide ühenduse (American Academy of Pediatrics ehk AAP) soovitusel $(1999,2011)$ ei tohiks nooremad kui 24 kuused lapsed ekraanimeediaga üldse kokku puutuda, ning kui neile seda siiski võimaldada, ei tohiks väikelaps ekraani ees viibida üle kahe tunni päevas. Andersoni ja Pempeki (2005) sõnul oli Ameerika lastearstide soovitus pärit ajast, mil väikelaste ekraanimeedia tarbimisest ja selle mõjust laste arengule teati üsna vähe. Aastal 2011 uuendas AAP oma soovitust, lisades ekraanimeedia hulka ka nutitelefonid ja puutetundlikud ekraanid. Sama moodi nagu Ameerika lastearstide ühendus, on ka Austraalia tervishoiuministeerium seda meelt, et alla 2aastastel lastel ei ole vaja ekraanimeediaga 
kokku puutuda. Austraalia ministeeriumi haldusesse kuuluv ühendus Get Up and Grow on välja toonud ajapiirangu, rõhutades, et 2-5aastased lapsed ei peaks ekraanimeediat tarbima üle ühe tunni päevas (Sweetser, Johnson, Ozdowska, \& Wyeth, 2012).

Ekraani ees veedetud ajaks või ekraaniajaks (screen time) loetakse mistahes elektroonilise seadmega veedetud aega. Sweetser ja tema kolleegid (2012) jagavad ekraaniaja passiivseks ja aktiivseks. Passiivset aega samastatakse televiisori vaatamisega, mille korral vaataja ei osale ekraanil toimuvate sündmuste loomises ega mõjuta neid. Aktiivne aeg seevastu võib tähendada nii kognitiivset kui ka füüsilist aktiivsust, nt arvutimängude mängimist või internetis surfamist (ibid.).

Ekraaniaja määratlusele tuginedes võib öelda, et tänapäevased ekraanid võimaldavad nii passiivset kui ka aktiivset tarbimist. Passiivset tarbimist ja selle mõju lastele on uuritud ligemale 70 aastat, laste televiisorivaatamise algusajast alates, kuid uuringuid, mis keskenduvad puutetundlike ekraanide kasutamisele väikelapseeas, on nähtuse uudsuse tõttu pigem vähe. Puutetundlikud ekraanid on olnud tavatarbijale kättesaadavad alles viis aastat ning see aeg ei ole võimaldanud korraldada pikiuuringuid selle kohta, millist mõju avaldavad puutetundlikud ekraanid väikelastele. Siiski on tehtud mõningaid uuringuid, mille fookuses on väikelaste võimed ja suutlikkus ekraanilt õppida.

Otsides vastust küsimusele, kas väikelapsed uue meedia vahendusel midagi õpivad, on uurijad esitanud nii poolt- kui ka vastuargumente. Vastuargumendina nimetavad uurijad (Anderson \& Pempek, 2005; Kuhl, Tsao, \& Liu, 2003), et väikelastel takistab ekraani vahendusel õppimist videodefitsiit, st väikelapsed õpivad päriselu kogemusest rohkem kui ekraanilt (Deloache \& Chiong, 2009). Teisisõnu on väikelastel keeruline käsitleda ja tõlgendada informatsiooni, mis jõuab nendeni ekraani kaudu, mistõttu õpivad nad ekraani vahendusel oluliselt vähem kui päriselu olukordades reaalsete inimeste ja objektidega kokku puutudes (nt Barr \& Hayne, 1999; Simcock \& DeLoache, 2006; Zack et al., 2009). Õppimine ekraanilt on raskendatud seetõttu, et pildiline meedium (pildid, videod, animatsioonid) põhineb sümbolitel, mida väikelapsed ei suuda enne 18. elukuud oma väheste kogemuste ning vähe arenenud tunnetuslike ja tajuprotsesside tõttu mõista, see aga takistab ekraani vahendusel õppimist (Courage \& Howe, 2010). Pildi sümbolilise olemuse mõistmine selle kahekordse esindatuse tõttu, mis tähendab erinevust pildi ja sellel kujutatu tähenduse vahel, ei ole väikelaste jaoks enne 3. eluaastat eakohane (Garrison \& Christakis, 2005; Krcmar, 2011). Alles 3. eluaastaks on laps suuteline jäljendama ekraanil nähtut sama efektiivselt kui päriselt nähtut, 
nt tantsu (Krcmar, 2011). Samas on uurijad (Sims \& Colunga, 2013) leidnud, et väikelapsed suudavad ekraani vahendusel óppida juhul, kui nutiseadme kasutamisse sekkub lapsevanem, kes suhtleb lapsega ja pöörab tema tegevusele verbaalset tähelepanu. Sel juhul võib ekraan pakkuda meelelahutusest märksa enamat. Samuti on leitud, et väikelapsed on suutelised ekraanilt õppima juhul, kui sisu on hästi disainitud ja neile arusaadaval viisil esitatud (Barr \& Hayne, 1999).

\section{Väikelapse suhtlus puutetundliku ekraaniga}

Tänapäeva kodud on tehnoloogia leviku ja kättesaadavuse poolest teinud läbi suured muutused. Personaalarvutid, kasutusmugavad operatsioonisüsteemid, mängukonsoolid ning internet on kujundanud kodust meediamaastiku (Aarsand, 2007), kus 60\% Eesti elanikkonnast on Riigi Infosüsteemide Ameti tellitud „Nutiseadmete kasutajate turvateadlikkuse ja turvalise käitumise uuringu" andmetel võimalik nutiseadmeid kasutada (TNS Emor, 2014).

Lapse ja arvuti interaktsioon (child computer interaction, CCI) on osa inimeste (kasutajate) ja arvutite vahelist suhtlust uurivast teadusdistsipliinist, mida nimetatakse inimese ja arvuti interaktsiooniks ehk IAIks (tuleneb sõnaühendist human computer interaction, HCI). Uuringud väikelaste ja arvutite interaktsiooni kohta on kinnitanud, et nutiseadmete rakendused peaksid olema eakohased ja vastama laste motoorsele arengule, sest vaid siis on nad efektiivsed (Aziz, 2013).

Arvutihiirt võib pidada väga heaks arvuti sisendseadmeks, kuid hiire käsitsemist tuleb sellest hoolimata õppida. Kui hiire esmakordne kasutamine võib nii mõnegi inimese segadusse ajada (Malizia \& Bellucci, 2012), takistab näiliselt lihtsa süsteemi kasutamist väikelaste puhul ka nende algeline peenmotoorika. Puutetundlik kasutajaliides (gesture interface) võimaldab loomulikku interaktsiooni, mida nimetatakse NUIks (natural user interface) ehk loomulikuks kasutajaliideseks, mille korral saab kasutaja sõrme või esemega ekraani puudutades ja esemeid liigutades seadmega suhelda (ibid.).

Puutetundliku ekraaniga seade on muutnud väikelapsele arvuti kasutamise lihtsamaks ning puutetundlikul tehnoloogial on traditsioonilisema hiire ja klaviatuuri ees óppimise kontekstis eelis (Disney, Barnes, McDowall, \& Geng, 2013). Segal (2011) rõhutab seejuures, et puutetundlik tehnoloogia pakub laiemaid võimalusi just seetõttu, et võimaldab õppimist füüsiliste liigutuste ja puudutuste kaudu, mida passiivsed interaktsioonid hiire ja klaviatuuriga ei võimalda. 


\section{Meediakasutuse sotsiaalne vahendamine ja lapsevanemate juhendamisstrateegiad}

Vanemlikku vahendamist on enamasti käsitletud televiisori vaatamise kontekstis. Vähem on uuritud seda, milliseid juhendamisstrateegiaid rakendavad vanemad laste arvuti- ja internetikasutamisel ehk kui palju vanemad reguleerivad, juhendavad või kontrollivad oma laste puhul uue meedia kasutust (Lee \& Chae, 2007).

Vanemlik vahendamine (parental mediation) on lai mõiste, mis hõlmab nii meediakasutuse piiranguid (nt aja- ja sisupiiranguid) kui ka strateegiaid, millega soovitakse ennetada meedia võimalikku negatiivset mõju. Üldiselt seostatakse vanemlikku vahendamist meedia positiivse mõju suurendamisega, mille eesmärk on kujundada lastest kriitilisemad meediatarbijad (Linder \& Werner, 2012; Livingstone \& Helsper, 2008; Vinter, 2013). Seega, meediakasutuse sotsiaalne vahendamine tähendab konkreetsete juhendamistegevuste ja -strateegiate kasutamist, mida suunavad vanemate hoiakud ja väärtused (Vinter, 2013). Vanemliku juhendamise mõju sõltub suures osas sellest, mis liiki juhendamisstrateegiaid vanemad kasutavad (Linder \& Werner, 2012).

Livingstone ja Helsper (2008) toovad oma uurimuses välja kolm peamist juhendamisstrateegiat: aktiivse (ka sotsiaalse, instrueeriva) juhendamise (active mediation), keelava juhendamise (restrictive mediation) ning koos kasutamise (co-using). Sarnaseid strateegiaid on nimetanud ka Nikken ja Jansz (2006), täiendades oma 2014. aasta uurimuses strateegiate loetelu jälgiva juhendamisega (supervision). Kalmus ja Roosalu (2011) lisavad sellesse loetellu ka monitooriva ehk seirava juhendamise (monitoring mediation) ja tehnilise juhendamise (technical restrictions/solutions). Seega saab rääkida üldjoontes kuuest juhendamisstrateegiast, millest kolm enim levinut on aktiivne ja keelav juhendamine ning koos kasutamine. Seejuures on vanemate strateegiad mõjutatud suuresti lapse vanusest (Nikken \& Jansz, 2014).

Aktiivne juhendamine toimub ajal, mil laps tarbib meedia sisu, ning hõlmab sisu üle arutlemist, et stimuleerida lapse mõtlemist ja mõistmist. Keelava juhendamisega kehtestatakse lapse meediatarbimisele eelkõige piiranguid või reegleid: vanem ei luba teatud sisuga programme kasutada, piirab meediatarbimise aega või keelab meediakasutuse kindlates kohtades. Koos vaatamine/kasutamine tähendab seda, et vanemad ja laps jagavad küll ühist meediakogemust, kuid vanem lapsega meedia sisu üle ei arutle ega kommenteeri seda (Livingstone \& Helsper, 2008). Jälgiv juhendamine võimaldab lapsel vanema läheduses olles meedia sisu vabalt tarbida / seadet 
iseseisvalt kasutada (Nikken \& Jansz, 2006). Monitoorimise ehk seirava juhendamise puhul kontrollivad vanemad lapse meediatarbimist veebilehtede ajaloo kontrollimise kaudu. Tehnilist juhendamist iseloomustab turvafiltrite ja jälgimistarkvara rakendamine eesmärgiga kasutada tarkvaralisi lahendusi lapse meediatarbimise kontrollimiseks, piiramiseks või jälgimiseks (Kalmus \& Roosalu, 2011). Sims ja Colunga (2013) toovad välja, et lapsed õpivad kõige tõhusamalt siis, kui vanemad reageerivad tema tegevusele kohe ja annavad talle tagasisidet. Seega soodustab laste õppimist ekraanilt vanemate samaaegne osavõtlik või kaasaelav käitumine, mistõttu on eelnimetatutest kõige efektiivsem aktiivne juhendamine.

Kokkuvõtvalt võib öelda, et laste kokkupuude nutiseadmetega algab juba imikueas ning puutetundlikud ekraanid võimaldavad lastel olla aktiivsed, mitte passiivsed tarbijad. Esimesed kolm eluaastat on lapse arengus väga oluline aeg ning seetõttu tuleks jälgida lapse meediamustreid väga varases arengustaadiumis. Väikelaste võime ekraanilt õppida ja ekraani vahendatud sisust aru saada on vähese elukogemuse, piiratud kognitiivsete võimete ja videodefitsiidi tõttu raskendatud. Siiski on leitud, et väikelapsed suudavad ekraani vahendusel óppida juhul, kui nutiseadme kasutamisse sekkub lapsevanem.

Artikli eesmärk on välja selgitada Eesti lapsevanemate hinnangud puutetundlike seadmete kasutamise vajalikkusele ning oma juhendamisstrateegiatele nutiseadme kasutamisel väikelapseeas. Vastuseid otsitakse järgmistele uurimisküsimustele.

1) Kui vajalikuks hindavad ja kuidas põhjendavad lapsevanemad puutetundliku ekraani kasutamist väikelapseeas?

2) Kui teadlikud on lapsevanemad laste puutetundlike ekraanide kasutamise ajast, seal olevast sisust ja vajalikust juhendamisest? Millist nõu vanemad vajaksid?

3) Kuidas lapsevanemad nende endi hinnangul juhendavad väikelast puutetundliku ekraani kasutamisel?

\section{Metoodika}

Valim

Uuringu valimi moodustasid 400 lapsevanemat, kellest naisi oli 91,5\% ja mehi 8,5\%. Valimisse kuulunud vanemate keskmine vanus oli 32 aastat (vastajaid oli 20.-50. eluaastani). Kirjaliku elektroonilise küsimustikuga kogutud andmed saadi 400 lapse kohta, kellest poisse ja tüdrukuid oli enam-vähem võrdselt: vastavalt 50,7\% ja 49,3\%. Kõige rohkem andmeid 
kogunes 31-36 kuu vanuste laste kohta (29,8\%). Enim vastanuid oli Harjumaalt - 43,8\%, Pärnumaalt oli 10\%, Tartumaalt 9,8\% ning kõige vähem vastanuid ehk alla 1\% oli Hiiumaalt, Põlvamaalt ja Valgamaalt. Harju-, Pärnu- ja Tartumaa kõrge vastanute protsent tuleneb ka lasteaedade rohkusest, sest vanematele edastati küsitluse link eelkõige lasteaedade kaudu e-kirja teel (73\%) ning sotsiaalmeediavõrgustiku Facebook kaudu (27\%). 49,5\% kõigist vastanud vanematest $(n=400)$ võimaldab lastele nutiseadmete kasutust ja 50,5\% ei võimalda, mis tähendab, et pooldajad ja vastased jagunevad ligikaudu pooleks.

\section{Protseduur}

Valimi moodustamiseks saadeti e-kiri kõigi Eesti lasteaedade direktoritele, kelle kontaktid on kättesaadavad Eesti.ee portaalis ja Eesti Hariduse Infosüsteemis. Direktorid said palve edastada küsitluse veebilink lapsevanematele, kelle lapsed käivad sama lasteaia sõimerühmas või kellel on kodus alla 3aastaseid lapsi. Isetekkelise valimi puhul jagati küsitluse veebilinki sotsiaalmeedia (Facebook) kogukondades ja gruppides eesmärgiga kaasata valimisse ka neid lapsevanemaid, kelle lapsed ei käi lasteaias, aga kellel on kodus kasvamas alla 3aastane laps. Seega kasutati kombineeritud valimi disaini. Veebipõhine ankeet valiti eelkõige kvantitatiivse andmekogumismõõdiku tugevuse tõttu, mis võimaldab koguda suure hulga andmeid ning tagab vastajate anonüümsuse (Hirsjärvi, Remes, \& Sajavaara, 2005; Mukherji \& Albon, 2010). Uuringus osalejad täitsid ankeedi elektrooniliselt keskkonnas Google. Uuring tehti 2014. aasta detsembris (04.12.1431.12.14). Andmeid analüüsiti tarkvaraprogrammiga Statistica 12.

Uuringus kasutati 0-3aastaste laste vanemate jaoks koostatud veebipõhist ankeeti, mis koosnes viiest osast. Esimeses osas uuriti väikelaste puutetundlike ekraanide kasutust ja piiranguid, mille väljaselgitamiseks kasutati küsimusi, mis tuginesid projektile „Technobabies” (O'Connor, 2014). Küsimusi oli kokku kümme. Likerti kuuepalliste skaalade abil selgitati välja, millised puutetundlikud vahendid on kodudes olemas, kui sageli neid kasutatakse ning mis rakendusi väikelapsed kasutavad. Avatud küsimused võimaldasid vastajatel lisada näiteid ja selgitusi.

Teine osa sisaldas küsimusi selle kohta, kuivõrd on vanemad teadlikud, millal, kus ja kui sageli väikelapsed puutetundlikke ekraane kasutavad, mis piirangud kasutamisega kaasnevad ja milline on rakenduste sisu. Küsimused tuginesid uuringus "Zero to eight” kasutatud skaaladele (Rideout, 2013). Teise osa küsimusi oli kokku 14. Vanemate seisukohti uuriti valikvastuste ja avatud küsimustega, et välja selgitada, kas ja mis tingimustel 
seavad vanemad lastele aja- ja sisupiiranguid ning kas vanemad on saanud infot ja juhiseid laste nutiseadmete kasutamise kohta.

Küsitluse kolmandas osas uuriti lapse arengu ja puutetundlike ekraanide mõju seost. Selleks kasutati kaheksat küsimust (nelja valikvastustega ja nelja avatud küsimust), mis põhinesid projekti „Technobabies” (O’Connor, 2014) mõõtmisvahendil.

Neljandas osas olid vanemate juhendamisstrateegiaid uurivad küsimused, mis toetusid Nikkeni ja Janszi (2006) uurimistulemustele. Uuringusse kaasati küsimused kolme juhendamisstrateegia kohta. Keelava juhendamise skaala (Likerti neljapalline skaala) põhines seitsmel küsimusel, millega mõõdeti, kui sageli vanemad jälgivad lapse käitumist nutiseadme kasutamise ajal, kui sageli nad kontrollivad ja hindavad rakenduste sobivust ja sisu ning kui sageli lapsi keelatakse. Aktiivse juhendamise skaala (Likerti neljapalline skaala) põhines neljal küsimusel, mille eesmärk oli välja selgitada, kui sageli vanemad suunavad lapse tähelepanu, annavad lapsele konkreetseid juhiseid, tagasisidet või suhtlevad lapsega ajal, mil laps nutiseadet kasutab. Koos vaatamise ja mängimise strateegia skaala (Likerti neljapalline skaala) põhines kolmel küsimusel, millega mõõdeti, kui sageli kasutavad vanemad koos lapsega nutiseadet või viibivad sel ajal lapse läheduses ja jälgivad vahendi kasutust.

Küsimustiku viiendasse ossa kuulusid küsimused, millega koguti sotsiaaldemograafilisi andmeid. Need puudutasid vanema sugu, vanust (sama ka lapse kohta), elukohta, kodust keelt ning haridustaset.

Kuna uuringus kasutatud skaalasid ei ole varem Eestis kasutatud, siis tõlkisid kaks sõltumatut uurijat küsimused eraldi, seejärel tehti prooviküsitlus seitsme lapsevanemaga. Vastajate kommentaaride alusel täiendati ja parandati küsimuste sõnastust. Andmeanalüüsis moodustati üksikküsimuste põhjal koondtunnused, võttes aluseks üksikväidete aritmeetilised keskmised. Selleks liideti kokku küsimuste keskväärtused ning aktiivse juhendamise puhul jagati summa kaheksaga ja keelava juhendamise puhul seitsmega. Kokku moodustati neli koondtunnust: „keelav juhendamine”, ,aktiivne juhendamine”, „vanema tegevus nutiseadmega (sagedus)” ning "lapse tegevus nutiseadmega (sagedus)”. Koondtunnused „keelav juhendamine” ja „aktiivne juhendamine” moodustati neljandas osas esitatud küsimuste kokkuliitmise teel (Likerti neljapallised skaalad). Küsimustega sooviti välja selgitada, mida teevad vanemad siis, kui laps nutiseadet kasutab. Koondtunnused „vanema tegevus nutiseadmega (sagedus)” ja "lapse tegevus nutiseadmega (sagedus)" moodustati esimeses osas esitatud küsimuste kokkuliitmise teel (Likerti kuuepalline skaala). Küsimused käsitlesid seadmete loetelu ja seda, kui sageli laps ja vanem seadmeid kasutavad. 
Küsimuste keskväärtused liideti kokku ning summa jagati viiega. Avatud küsimustele antud vastuseid kasutati uurimuses lisanäidetena.

\section{Tulemused}

Tulemuste analüüsimisel moodustati neli koondtunnust. „Keelav juhendamine" näitab, mil määral vanemad rakendavad lapse nutiseadme kasutamisele piiranguid või reegleid. Tunnus "aktiivne juhendamine” kirjeldab, mil määral vanem arutleb meedia sisu üle, et stimuleerida lapse mõtlemist ja mõistmist. „Lastele nutiseadmete kasutust võimaldava vanema tegevus nutiseadmega (sagedus)" väljendab, kui sageli vanemad, kes lubavad lastel nutiseadmeid kasutada, kasutavad ka ise nutiseadmeid. „Lapse kokkupuude nutiseadmega (sagedus)" näitab, kui tihti võimaldatakse lapsele nutiseadme kasutust.

Varasemates uurimustes välja toodud kolm juhendamisstrateegiat (keelav, aktiivne ja koos tegutsemise strateegia) siinse valimi puhul selgelt ei eristu. Seetõttu ei ole juhendamisstrateegiate detailsemal käsitlemisel ülalnimetatud kolme strateegiat eraldi analüüsitud.

Tabel 1. Koondtunnuste kirjeldavad statistikud

\begin{tabular}{l|c|c|c|c|c|c}
\hline Skaala & $N$ & $M$ & Min & Max & SD & Cronbachi $a$ \\
\hline $\begin{array}{l}\text { Lastele nutiseadmete kasutust } \\
\text { võimaldava vanema tegevus } \\
\text { nutiseadmega (sagedus) }\end{array}$ & 400 & 1,95 & 0 & 5,7 & 2,07 & 0,94 \\
\hline $\begin{array}{l}\text { Lapse kokkupuude nutiseadmega } \\
\text { (sagedus) }\end{array}$ & 400 & 2,46 & 0 & 5,8 & 2,51 & 0,97 \\
\hline $\begin{array}{l}\text { Lapse tegevus nutiseadmega } \\
\text { (sagedus) }\end{array}$ & 400 & 2,34 & 0 & 6,0 & 2,42 & 0,97 \\
\hline $\begin{array}{l}\text { Lastele nutiseadmete kasutust } \\
\text { mittevõimaldava vanema tegevus } \\
\text { nutiseadmega (sagedus) }\end{array}$ & 400 & 1,93 & 0 & 5,9 & 2,14 & 0,95 \\
\hline
\end{tabular}

Märkus. $N=$ vastanute arv, $M=$ keskmine tulemus, $\min =$ minimaalne tulemus, $\max =$ maksimaalne tulemus, $S D=$ standardhälve, $a=$ Cronbachi alfa.

Tabelis 1 on toodud analüüsis kasutatud koondtunnuste kirjeldavad statistikud ning skaalade sisemise reliaabluse (homogeensuse) näitaja Cronbachi alfa. Koondtunnuste reliaablus oli piisavalt suur (vahemikus 0,94-0,97), mis lubab neisse koondatud küsimusi kasutada ühtse näitajana. 


\section{Nutiseadmete kasutamine väikelaste hulgas ja selle põhjused}

Esimene uurimisküsimus keskendus sellele, kas lapsevanemad lubavad või ei luba väikelastel puutetundlikku ekraani kasutada ning mis on selle põhjused. Kõigist vastanutest $(n=400)$ võimaldavad oma lapsel kasutada nutiseadet $49,5 \%$, kuid 50,5\% vanematest ei võimalda.

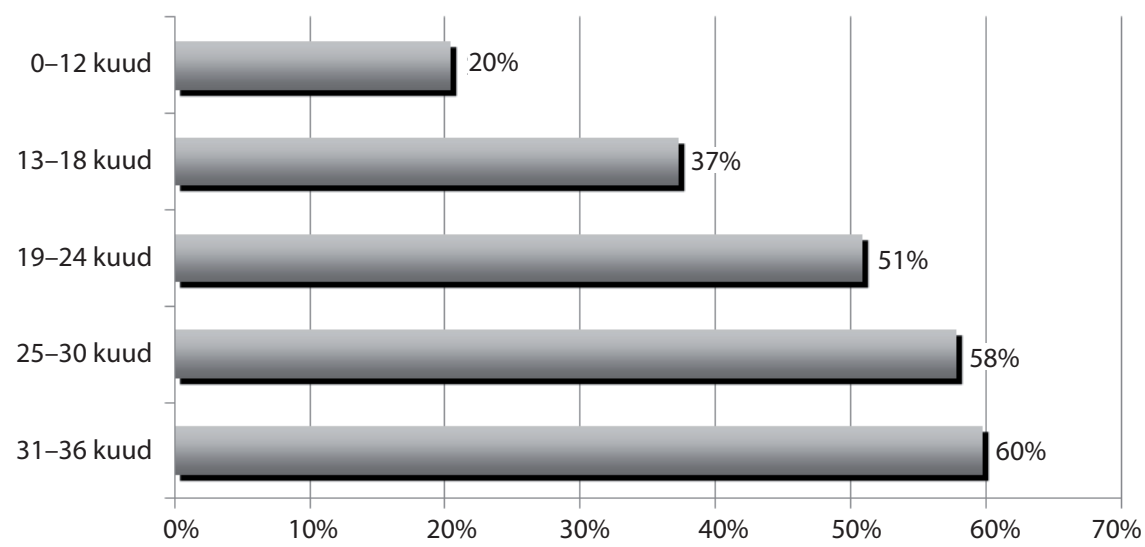

Joonis 2. Laste vanuseline jaotus (lapsed, kellele võimaldatakse nutiseadme kasutust)

Joonisel 2 on toodud laste vanuseline jaotus, kust ilmneb, et lapse vanuse kasvades sageneb ka nutiseadmete kasutus. Samale tendentsile viitab vahendi kasutuse juhendamise kohta käiv korrelatsioonanalüüs, mille kohaselt on lapse vanuse ja juhendamise vaheline seos statistiliselt oluline $(r=0,28, p<0,05)$ ning mis näitab, et lapse vanuse kasvades rakendatakse enam vanemlikku juhendamist.

Vanemad näevad nutiseadme kasutamise eelistena ja positiivse mõjuna seda, et laps õpib uusi oskusi (67,7\%) ja saab uusi teadmisi (53\%) ning nutiseade pakub meelelahutust ja lõbustab last $(55,1 \%)$. Lapsevanematest, kes oma lastele nutiseadmeid võimaldavad $(n=198)$, on $58,1 \%$ seadme kasutamise ajal alati lapse läheduses, 59,6\% kontrollib rakenduse sobivust, 52\% jälgib lapse käitumist ning 45,5\% loeb rakenduste sisukirjeldusi. Seega tehakse aktiivse juhendamisega seotud tegevusi (lapse läheduses viibimine ja rakenduste sobivuse kontrollimine) sagedamini kui keelava juhendamisega seotud tegevusi (lapse käitumise jälgimine ja rakenduste sisukirjelduste lugemine). Vanemad, kes ei võimalda oma lastele nutiseadme kasutust $(n=202)$, toovad keelu põhjuseks eelkõige selle, et nutiseade rikub lapse silmi (55,9\%), mõjub negatiivselt nii lapse ja vanema (52,5\%) kui ka kogu pere (53\%) omavahelisele suhtlusele. 


\section{Lapsevanemate teadlikkus nutiseadmete kasutamisega seotud aspektidest}

Teise uurimisküsimuse eesmärk oli välja selgitada, kui teadlikud on vanemad laste puutetundlike ekraanide kasutamise ajast, meedia sisust ja vajalikust juhendamisest ning sellest, millist nõu nad vajaksid. Võrreldes seda, kui sageli laps nutiseadmega kokku puutub ja seda kasutab, võib öelda, et vanemate sõnul ( $n=198)$ kasutavad lapsed iga päev kõige enam nutitelefoni $(39,4 \%)$ ja tahvelarvutit $(25,2 \%)$, ning seda eelkõige videote, multifilmide või TV-saadete vaatamiseks $(31,8 \%)$. Samas kasutavad lapsed väga harva (30\%) või mitte kunagi (46\%) mitut meediakanalit korraga.

Korrelatsioonanalüüsi tulemused osutavad, et see, kui sageli lapsevanem ja laps nutiseadet kasutavad, on positiivselt seotud $(r=0,29, p<0,05)$, teisisõnu, mida sagedamini kasutab vanem nutiseadmeid, seda sagedamini teeb seda ka laps. Lapsevanemate sõnul kasutavad lapsed kõige enam YouTube’i, mille vahendusel vaadatakse nii videoid, multifilme kui ka telesaateid. Kõige enam nimetati multifilmidest „Mašat ja karu”, mängurakendustest Talking Tomi, tegevustest piltide vaatamist ning suhtlusrakenduste Skype ja Facetime kasutamist. Lisaks tõid vanemad välja konkreetseid rakendusi, mida väikelapsed kasutavad (Toca Boca, Angry Birds, LEGO Duplo, Animal Numbers, Animal Memory, Draw+Coloring, Toddler Coloring, Turtle Math, ABC Turtle, Tere-tere, Kids Doodle, MyZoo, Findus Inventions 2, Busy Shapes, Subway Surf, Baby Piano, Animal Sounds for Baby, Duckie Deck, Sound Touch Lite, Zoo Sounds, Tony the Truck).

Vanemate nimetatud rakendustest võib väikelastele sisu poolest eakohasemaks pidada TocaBoca mänge, mis on lisatud POSCONi (positiivne meediasisu lastele) nimekirja ning mis toetavad laste kujutlusvõimet ja loovust. Rakendus Talking Tom kujundab ühest küljest küll hoolivust ja empaatiavõimet, teisalt sisaldab aga tegevusi, mis õhutavad vägivalda kasutama ja võivad kujundada vildakaid väärtushinnanguid (kassile saab haiget teha teda kõhtu lüües või lükates). „Maša ja karu” on Eesti riigitelevisiooni ETV2 lasteprogrammis liigitatud lastesõbralikuks multifilmiks, mis sisu poolest vajab vanemlikku juhendamist.

Vanematest, kes võimaldavad lastele nutiseadme kasutamist $(n=198)$, on juhendamist saanud $33,8 \%$. Info pärineb valdavalt internetist $(24,7 \%)$ ja ajakirjadest/ajalehtedest $(20,2 \%)$. Nendest vanematest, kes ei võimalda oma lastel nutiseadet kasutada $(n=202)$, on juhendamist saanud $24,8 \%$. Info on samuti pärit valdavalt internetist (16,33\%) ning ajakirjadest/ajalehtedest $(15,34 \%)$. Perearstilt ja sõimeõpetajalt (juhul kui laps käib sõimes) on vanemad infot saanud/küsinud märkimisväärselt vähe (2\%). Seega on vähem 
kui pooled vastanud vanematest $(29,5 \%)$ saanud laste nutiseadmete kasutamise kohta infot ja asjakohaseid juhiseid. Vanemad kasutavad infoallikana enamasti internetti ja trükiväljaandeid ning küsivad infot pigem sõpradelt kui perearstilt või sõimeõpetajalt. Vanemad, kes on saanud rohkem juhendamist, võimaldavad oma lastele nutiseadmetega suuremat vabadust.

Uuring näitas, et vanematel on laste juhendamisega seoses tekkinud mitmesuguseid küsimusi ja muresid, mis on seotud vahendatava sisu, nutiseadme kasutamise aja ning lapse tervise ja ohutusega. Sisu puhul soovivad vanemad enam infot selle eakohasuse ja arengu soodustamise kohta. Kasutamisajaga seoses tuntakse end ebakindlalt küsimustes, mis puudutavad nutivahendi kasutamise optimaalset aega, ning muretsetakse lapse ohutuse ja tervise pärast, mis on seotud laste närvilisuse, seadmete läheduses viibimise (kiirguse jms), terviseohtude ja muuga. Samuti ootavad vanemad üldisi pedagoogilisi ja lapse arengut puudutavaid soovitusi.

Endale tundub segadust tekitav arusaamine, et milline on tema maailmakogemuse erinevus minu omast, kui ta on harjunud libistama ja suurendama ekraani, ning milline on reaalsusetaju erinevalt minu omast ja kas suudab vahet teha ekraanitaguse ja pärismaailma vahel. (30kuuse poisi vanem)

Nõuandeid, kuidas laps ei jonniks, selle pärast et mõni multikas vmt kinni pannakse või tahvelarvuti käest võetakse. (28kuuse poisi vanem)

Kas telefonid - nuti- või tavalised - on ohtlikud minu lapse tervisele? Kas tuleks vältida nende keha läheduses hoidmist? (26kuuse poisi vanem)

Pole väga leidnud toredaid eestikeelseid rakendusi just väikestele. (30kuuse tüdruku vanem)

Eeltoodust ilmneb, et ehkki vanemad märkavad, mida lapsed nutiseadmeid kasutades teevad, on nende päralt siiski üsna vähe infot, mis aitaks neil nutiseadmete vahendusel lapseni jõudvat maailma harivaks ja arendavaks muuta. Hoolimata sellest leiavad nutiseadmeid võimaldavad vanemad üsna optimistlikult, et nutiseadmed avaldavad lapse arengule positiivset mõju.

\section{Lapsevanemate hinnangud juhendamisstrateegiatele}

Kolmas uurimisküsimus keskendus sellele, kuidas lapsevanemad juhendavad väikelast puutetundliku seadme kasutamisel. Lapsevanemate juhendamisstrateegiate põhjalikumaks väljaselgitamiseks küsiti, milliseid sisu- ja ajapiiranguid rakendavad vanemad lastele nutiseadmete kasutamisel, ning 
avatud vastused võimaldasid täpsustada enda tegevust. Nutiseadmete kasutamist võimaldavate vanemate $(n=198)$ vastuste põhjal kuuluvad lapsevanemad aja- ja sisupiirangute seadmise poolest kolme rühma. Esimest tüüpi esindavad vanemad, kes seavad nii aja- kui ka sisupiiranguid (56,6\%). Teist tüüpi vanemad seavad lastele ühte liiki piiranguid: kas ajalisi $(22,7 \%)$ või sisulisi $(6,6 \%)$. Kolmandat tüüpi vanemad ei sea lastele mingisuguseid piiranguid $(14,1 \%)$. Seega piiravad üle poole vastanutest oma lapse nutiseadmete kasutust nii ajaliselt kui ka sisuliselt.

Vanemate vastuste kategoriseerimisel selgus, et sisupiirangud puudutavad kõige enam vägivaldseid videoid, multikaid ja mänge. Keelatud sisuna tõid vanemad välja töödokumendid ja rakendused, mis ei ole küll vägivaldse sisuga, aga on lapsele keelatud, sest need pole eakohased. Samuti mainiti, et lapsel ei ole lubatud kasutada helistamise ja sõnumi saatmise rakendusi.

Kui vägivaldse sisuga rakendused, videod ja mängud on keelatud, siis lubatud tegevusteks, mida vähem piirati, on multifilmide (nt „Maša ja karu") ja videote vaatamine (YouTube) ning piltide vaatamine ja tegemine. Vanemad, kes lastele sisupiiranguid ei sea, põhjendasid seda sellega, et laps on ise piisavalt nutikas, et leida üles endale meeldiv sisu. Samuti kaitstakse last sellega, et lülitatakse nutiseadme kasutamise ajaks internet välja, leides, et see on lapse kaitsmiseks piisav. Ajapiirangute kategoriseerimisel selgus, et vanemad rakendavad laste puhul täpseid ajapiiranguid vahemikus 10 minutit kuni paar tundi päevas.

Kuidas on tuju ja käitumine, vastavalt sellele kas ei saa üldse mängida või $10 \mathrm{~min}$ õhtu kohta. 10 min peale päevast magamist. (36kuuse tüdruku vanem)

Enamasti saab laps mängida 5-10 minutit korraga. Vahel paar korda päevas. Kui on lühem aeg, siis summeerin. Üle 30 minuti ei taha lasta lapsel seadmega jännata. (35kuuse poisi vanem)

Luban lapsel nutiseadet näppida, kui pean ise korraks millegi muuga tegelema (arveid maksma, süüa tegema). Samas ta lihtsalt nagunii hoiab seda, mitte ei kasuta sisuliselt. (13kuuse poisi vanem)

Üritan keelata, kui liiga kaua on, aga sellest ei tule midagi välja. (22kuuse tüdruku vanem)

Nutiseadme kasutuse võimaldamise põhjuseks osutus teatud puhkudel koht (nt ootejärjekord, külas olemine, transpordivahend). Nutiseadet kasutatakse enamasti distsipliini hoidmise vahendina või võimaldatakse 
nutiseadme kasutamist lapsele tema jaoks päevarutiini hoidmist toetava tegevusena (nt magamaminek, lasteaiapäeva lõpetamine).

Vanemate selgitused aja- ja sisupiirangute kohta viitasid muu hulgas tehnilisele juhendamisele, mida uuringutes kasutatud skaaladega ei mõõdetud. Tehniliste piirangutena rakendatakse mõningate rakenduste ja mängude korral vanemlikku kontrolli (parental control), kasutatakse nutiseadme parooli või lapserežiimi, kus vanem on määranud, mis rakendusi laps saab kasutada, ning kehtestatakse ajaline režiim, mis võimaldab seadme kasutamist ainult ettenähtud ajavahemikul.

T-testi tulemusena selgus, et sisupiiranguid seadvate $(M=4,82 ; S D=$ $0,71)$ ja mitteseadvate lapsevanemate $(M=4,58 ; S D=0,82)$ rühma vahel esineb statistiliselt oluline erinevus. Perekondades, kus vanemad seavad sisupiiranguid, kasutavad lapsed nutiseadmeid sagedamini, $t(196)=2,1$; $p<0,05$. Keskmise väiksem väärtus tähistab nutiseadme kasutamise suuremat sagedust. T-testi põhjal ilmnes, et ajapiiranguid seadvate $(M=4,78$; $S D=0,69)$ ja mitteseadvate lapsevanemate $(M=4,52 ; S D=0,95)$ rühma erinevus on samuti statistiliselt oluline. Perekondades, kus vanemad seavad ajapiiranguid, kasutavad lapsed nutiseadmeid sagedamini, $t(196)=2$; $p<0,05$. Keskmise väiksem väärtus tähistab nutiseadme kasutamise suuremat sagedust. Seega kasutavad lapsed peredes, kus vanemad seavad lastele nii aja- kui ka sisupiiranguid, nutiseadmeid sagedamini kui nendes peredes, kus piiranguid ei seata.

\section{Arutelu}

Uuringud on näidanud, et väikelapsed puutuvad digitaaltehnoloogiliste vahenditega kokku juba enne esimest eluaastat (Holloway et al., 2013; Rideout \& Hamel, 2006; Suoninen, 2013). Uuritud valimi puhul jagunes nende laste hulk, kellele ei lubata nutiseadmeid (50,5\%), peaaegu võrdselt nendega, kellele lubatakse $(49,5 \%)$, mis kinnitab uurijate varasemaid tulemusi.

Põhjused, miks vanemad lastele nutiseadmeid lubavad või keelavad, ei lange kokku lapse arengu seaduspäradega väikelapseeas. Vanemate vähesele teadlikkusele asjaolust, et ekraanilt õppimist takistab väikelapse arengulise eripärana videodefitsiit (Anderson \& Pempek, 2005; Kuhl et al., 2003), osutasid ka praegused uurimistulemused. Nutiseadme kasutamist võimaldades lähtuvad vanemad eelkõige sellest, et peavad meedia sisu arendavaks (lapsed omandavad uusi oskusi ja teadmisi). See seisukoht ühtib varasemate uurimuste tulemustega (Courage \& Howe, 2010; Vinter, 
2013), millest on selgunud, et lapsevanemad soosivad digitaaltehnoloogiliste vahendite kasutamist eelkoolieas, rõhutades nende arendavat mõju. Esimesel kolmel aastal on lapse areng väga kiire, mistõttu võivad vanemad pidada nutiseadet ja seal olevat sisu arendavaks, kuigi need ei pruugi tegelikult lapse arengule mingisugust mõju avaldada (Deloache \& Chiong, 2009). Samas kinnistab see arusaama, et nutiseadmete sagedane kasutamine on lapse arengule ja õppimisele ka tulevikku silmas pidades pigem kasulik. Samamoodi nagu 2013. aastal tehtud uuringus eelkooliealiste laste vanemate seas (Vinter, 2013), nimetasid ka praegu väikelaste vanemad nutiseadmete keelamise peamise põhjusena terviseriske ja vähem sotsiaalseid aspekte, tuues välja, et nutiseadmed rikuvad lapse silmi.

Vanemate teadlikkus puutetundlike ekraanide kasutamise ajast, seal olevast sisust ning vajalikust juhendamisest sõltub lapse vanusest. Praeguse uuringu tulemused kinnitavad 2010. aastal korraldatud uuringu "Children's media barometer" tulemusi (Kotilainen, 2010), mille kohaselt suureneb lapse vanuse kasvades ka nutiseadme kasutamise sagedus. Nii nagu Nikkeni ja Janszi (2014) uurimus, viitavad ka siinsed tulemused, et see, kui sageli kasutavad vanemad ja lapsed nutiseadmeid, on omavahel seotud - mida sagedamini kasutab vanem nutiseadmeid, seda sagedamini teeb seda ka laps.

Väikelapsed kasutavad nutitelefoni ja tahvelarvutit eelkõige videote, multifilmide või TV-saadete vaatamiseks. Siinkohal ühtivad tulemused Soomes tehtud uuringute omadega (Suoninen, 2013), välja arvatud rakenduste ja tegevuste poolest: Soomes tehtud uuringust selgus, et väikelapse meediakogemus algab muusika kuulamise ja raamatu ettelugemisega, kuid Eesti vanemate seas tehtud uuring osutab lubatud ja eelistatud sisuga multifilmide, videoklippide ja piltide vaatamisele ning piltide tegemisele. Muusika kuulamist ja raamatute ettelugemist esines uuritud sihtrühma puhul minimaalselt. Samas levis vanemate seas arvamus, et laps on ise piisavalt nutikas, et leida üles endale meeldiv sisu. Ka Soome tulemustest (Suoninen, 2013) ilmneb, et väikelapsed kasutavad puutetundlikke ekraane valdavalt täiskasvanu seltsis, kuid neil lastakse seadmega ka iseseisvalt toimetada.

Vanemad, kes on end ise väikelaste arengu ja nutiseadmete kasutamisega kurssi viinud, võimaldavad oma lastele nutiseadmega rohkem vabadust. Varasematest uuringutest (Kalmus \& Roosalu, 2011; Livingstone \& Helsper, 2008; Nikken \& Jansz, 2006, 2014) on selgunud, et peamised strateegiad, mida vanemad laste internetikasutuse juhendamisel rakendavad, on aktiivne juhendamine, keelav juhendamine, koos vaatamine, jälgiv juhendamine, monitoorimine ning tehniline juhendamine. Praegusest 
uuringust ilmnes, et kasutatud valimi puhul ei eristunud juhendamisstrateegiate skaala põhjal puhtaid strateegiaid, mis võib viidata sellele, et väikelaste juhendamise mustrid on oma laadilt teistsugused. Seda, miks juhendamismustrid ei eristunud selgelt, võib seletada eelnimetatud uuringutes osalenud laste vanusega: valimisse kuulunud laste vanus jäi vahemikku 2-18 eluaastat. Praegusesse uuringusse olid kaasatud alla kolmeaastased lapsed. Siiski kattuvad tulemused Nikkeni ja Janzsi (2014) uuringu tulemustega, mis viitavad uut tüüpi juhendamisstrateegiale jälgivale juhendamisele (supervision), mille korral on vanemad ühitanud majapidamistööd uue meedia kasutamisega, jättes lapsele vabaduse toimetada nutiseadmega iseseisvalt, kuid nad jälgivad piisavast kaugusest lapse tegevust.

Üle poole vastanutest $(56,6 \%)$ piirab lapse nutiseadme kasutust nii ajaliselt kui ka sisuliselt. Samas ilmneb tendents, et mida vanem on laps, seda rohkem rakendatakse vanemlikku juhendamist. See on põhimõtteliselt vastuolus ekraanilt õppimise ühe mõjuvõimsama aspektiga - mida väiksem laps, seda vähem ta iseseisvalt ekraanilt õpib ning seda olulisem on vanema aktiivne osalus ja juhendamine (Sims \& Colunga, 2013), et kompenseerida videodefitsiidist põhjustatud ealist iseärasust ekraanisisu mõistmisel.

Uuringust selgus, et nutiseadmeid nähakse abivahendina, mis võimaldavad lapsevanemale aega isiklikeks tegevusteks. Samas on vanemad ajal, mil laps nutiseadet kasutab, lapse läheduses ja jälgivad tema käitumist. See osutab taas kord sellele, et väikelaste puhul rakendub pigem uut tüüpi juhendamine, mille korral ühitavad vanemad majapidamistööd jälgiva juhendamisega ning lapsel on vabadus toimetada nutiseadmega iseseisvalt (Nikken \& Jansz, 2014).

Uuringu puudusena võib välja tuua mitteesindusliku valimi, mis ei võimaldanud teha üldistusi kogu Eesti kohta. Samas võimaldas valim võrrelda eri rühmi ja analüüsida muutujatevahelisi seoseid, mis näitasid mitmel puhul statistiliselt olulisi suundumusi. Uurimisvahendi (veebiküsitluse) miinuseks võib pidada sõltumist internetiühenduse olemasolust. Kuna püsiühendusega internetti kasutab 89\% Eesti elanikest ning 97\% Eesti territooriumist katab 4G levi (Konkurentsiamet, 2013), ei tohiks see siiski olla määrava tähtsusega. Teiseks miinuseks on vastaja usaldusväärsuse tuvastamine, sest erinevalt intervjuust või telefoniküsitlusest ei saa küsitluse puhul olla ankeedile vastaja isikus kindel (Mukherji \& Albon, 2010), mistõttu võib küsitlusega kaasneda andmete risustamine. Siiski võib eeldada, et andmed nutiseadmete kasutamise kohta sisestas vanem ise, sest nii noore sihtrühma puhul on väga väike tõenäosus, et keegi teine võiks neid andmeid teada. 


\section{Kokkuvõte}

Uurimistulemuste põhjal võib väita, et vanemad, kes võimaldavad väikelastele nutiseadmete kasutust, tajuvad eelkõige selle arendavat rolli ning võimalust last n-ö ohutu hoidja juurde jätta. Samavõrd on vanemaid, kes ei võimalda oma lapsele nutiseadme kasutust, sest tajuvad riski lapse silmadele ning on seisukohal, et nutiseade mõjub negatiivselt nii lapse ja vanema kui ka kogu pere omavahelisele suhtlusele. Nutiseadme kasutamine väikelapseeas sõltub sellest, kuidas vanemad nutiseadmeid kasutavad, seega mida sagedamini vanem nutiseadmega tegutseb, seda sagedamini teeb seda ka laps. Kuna vanem on oma lapsele eeskujuks, peaks ta hoolikalt jälgima, kui sageli ja kaua ta ise nutiseadet kasutab. Peamiselt vaatavad väikelapsed nutitelefonide ja tahvelarvutite vahendusel YouTube'ist videoklippe.

Vanemad vajaksid rohkem infot nutiseadmete kasutuse juhendamise kohta ning on huvitatud pedagoogilistest soovitustest ja nõuannetest, mis on seotud eelkõige arendava ja eakohase sisu, optimaalse aja ning seadme ohutu kasutamisega. Lapse puhul saab vanem rakendada nii aja- kui ka sisupiiranguid, mis võimaldavad juba varases eas luua aluse kokkulepeteks, mis tingimustel nutiseadmeid kasutatakse. Väikelapse esimesel kolmel eluaastal toimuvad olulised muutused lapse vaimses, emotsionaalses ja füüsilises arengus, kuid alla kolmeaastane laps ei vaja ekraanimeediat, et ümbritsevat maailma paremini tundma õppida või kognitiivselt ja motoorselt kiiremini areneda. Väikelaps õpib peamiselt reaalse elu kogemustest, mis ei ole meedia vahendatud, vaid kõigi meeltega tajutavad. Siiski on puutetundlik ekraan tänapäeva väikelaste elu lahutamatu osa ning lapsele seadet võimaldades tuleks tähelepanu pöörata eeskätt meedia sisule ja lapse juhendamisele, mitte niivõrd piirangutele. Uurimistulemuste põhjal võib öelda, et ka sõimeõpetajate sõnum lapsevanematele peaks olema eelkõige see, et nutiseade ei peaks täitma lapsehoidja rolli - vanema ülesanne on juhendada lapse sisuvalikuid ja ajakasutust.

Tulemused viitavad, et vanemad otsivad infot väikelaste ja nutiseadmete kohta pigem internetist, ajakirjadest ja ajalehtedest, kui küsivad seda sõimeõpetajalt või lastearstilt. Seetõttu tuleks õpetajakoolituses käsitleda nutiseadmete võimalikku mõju lapsele ja nende rolli kasvukeskkonna kujundajana. Samuti on uurimistulemused olulised nutiseadmete rakenduste loojatele ja disaineritele, kes soovivad töötada väikelastele välja hariduslikke ja arendavaid mänge. Vähese vanemliku juhendamise korral ei täida mängud arendavat eesmärki, mistõttu tuleks rakendusi luues arvestada asjaoluga, et ka lapsevanem peaks saama nutiseadmega mängimisest osa võtta. 
Uurimistulemused ja lapsevanemate antud vastused osutavad vajadusele teha lisauuringuid, et välja selgitada, mil määral rakendavad alla kolmeaastaste laste vanemad jälgivat (supervision) ja monitoorivat juhendamist, sest nii noore sihtrühma puhul ei rakendanud vanemad aktiivset ja keelavat juhendamist nii konkreetselt, kui see ilmnes varem korraldatud uuringutes vanemate lastega. Pigem kasutavad vanemad nii aktiivse kui ka keelava juhendamise elemente samal ajal ja omavahel seotult. Kuigi uurimise tulemusena tulid küll ilmsiks mõningad jälgiva ja tehnilise juhendamise strateegiad, vajaks teema siiski põhjalikumat käsitlemist. Vaatluse alla võiks võtta eelkõige 2,5-3aastased lapsed, sest selle vanuserühma puhul eeldab nutiseadmete kasutamine vanemlikku juhendamist kõige enam, et nutiseadmed avaldaksid lapsele arendavat ja õpetavat mõju.

\section{Tänusõnad}

Suur tänu Mati Heidmetsale STATISTICA programmi kasutamisega seotud nõuannete eest.

\section{Kasutatud kirjandus}

Aarsand, P. A. (2007). Computer and video games in family life: The digital divide as a resource in intergenerational interactions. Childhood, 14(2), 235-256. doi: http://dx.doi.org/10.1177/0907568207078330

American Academy of Pediatrics (1999). Media education. Pediatrics, 104(2), 341343. Retrieved from http://pediatrics.aappublications.org/content/104/2/341.full. pdf+html. doi: http://dx.doi.org/10.1542/peds.104.2.341

American Academy of Pediatrics (2011). Media use by children younger than 2 years. Pediatrics, 128(5), 1040-1045. Retrieved from http://pediatrics.aappublications.org/content/early/2011/10/12/peds.2011-1753.full.pdf+html. doi: http://dx.doi.org/10.1542/peds.2011-1753

Anderson, D. R., \& Pempek, T. A. (2005). Television and very young children. American Behavioral Scientist, 48(5), 505-522. doi: http://dx.doi.org/10.1177/0002764204271506

Aziz, N. A. A. (2013). Children's interaction with tablet applications: Gestures and interface design. International Journal of Computer and Information Technology, 2(3), 447-450.

Barr, R. (2013). Memory constraints on infant learning from picture books, television, and touchscreens. Child Development, 7(4), 205-210. doi: http://dx.doi.org/10.1111/cdep.12041

Barr, R., \& Hayne, H. (1999). Developmental changes in imitation from television during infancy. Child Development, 70(5), 1067-1081.

doi: http://dx.doi.org/10.1111/1467-8624.00079 
Bransford, J., Brown, A. L., \& Cocking, R. R. (Ed.). (2000). How people learn: Brain, mind, experience, and school. Washington, D.C.: National Academies Press. Retrieved from http://www.nap.edu/openbook.php?isbn=0309070368.

Cardany, A. B. (2010). Screen media and young children: Who benefits? General Music Today, 24(1), 50-55. doi: http://dx.doi.org/10.1177/1048371310377598

Christakis, D. A. (2009). The effects of infant media usage: What do we know and what should we learn? Acta Podiatrica, 98(1), 8-16. doi: http://dx.doi.org/10.1111/j.1651-2227.2008.01027.x

Courage, M. L., \& Howe, M. L. (2010). To watch or not to watch: Infants and toddlers in a brave new electronic world. Developmental Review, 30(2), 101-115. doi: http://dx.doi.org/10.1016/j.dr.2010.03.002

Deloache, J. S., \& Chiong, C. (2009). Babies and baby media. American Behavioral Scientist, 52(8), 1115-1135. doi: http://dx.doi.org/10.1177/0002764209331537

Disney, L., Barnes, A., McDowall, J., \& Geng, G. (2013). Observation of children's engagement when playing iPads. Proceedings of 21st International Conference on Computers in Education (ICCE 2013), Bali, Indonesia, 18 to 22 November, 602-607. Retrieved from https://espace.cdu.edu.au/view/cdu:40223.

Garrison, M., \& Christakis, D. A. (2005). A teacher in the living room: Educational media for babies, toddlers, and preschoolers. The Henry J. Kaiser Family Foundation. Retrieved from https://kaiserfamilyfoundation.files.wordpress.com/2013/01/7427.pdf.

Gopnik, A., Meltzoff, A. N., \& Kuhl, P. K. (2003). Kuidas beebid mõtlevad: uurimus lapsepõlvest. Tallinn: Eesti Ekspressi Kirjastus.

Hirsjärvi, S., Remes, P., \& Sajavaara, P. (2005). Uuri ja kirjuta. Tallinn: Medicina.

Holloway, D., Green, L., \& Livingstone, S. (2013). Zero to eight: Young children and their internet use. LSE, London: EU Kids Online Report. Retrieved from http://eprints.lse.ac.uk/52630/1/Zero_to_eight.pdf.

Kalmus, V., \& Roosalu, T. (2011). Parental mediation of EU kids' internet use revisited: Looking for a complex model of cross-national differences. International Journal of Media \& Cultural Politics, 7(1), 55-66.

Konkurentsiamet (2013). Aastaraamat 2013. Külastatud aadressil http://www.konkurentsiamet.ee/public/Aastaraamat/Aastaraamat_2013.pdf.

Kotilainen, S. (2010). Children's media barometer 2010: The use of media among 0-8-year-olds in Finland. Retrieved from http://www.mediakasvatus.fi/publications/ISBN978-952-99964-7-6.pdf.

Krcmar, M. (2011). Can past experience with television help US infants learn from it? Journal of Children and Media, 5(3), 235-247. doi: http://dx.doi.org/10.1080/17482798.2011.584373

Kuhl, P. K., Tsao, F.-M., \& Liu, H.-M. (2003). Foreign language experience in infancy: Effects of short-term exposure and social interaction on phonetic learning. Proceedings of the National Academy of Sciences of the United States of America, 100(15), 9096-9101. doi: http://dx.doi.org/10.1073/pnas.1532872100

Lee, S.-J., \& Chae, Y.-G. (2007). Children's internet use in a family context: Influence on family relationships and parental mediation. CyberPsychology \& Behavior, 10(5), 640-644. doi: http://dx.doi.org/10.1089/cpb.2007.9975 
Linder, J. R., \& Werner, N. E. (2012). Relationally aggressive media exposure and children's normative beliefs: Does parental mediation matter? Family Relations. Interdisciplinary Journal of Applied Family Studies, 61(3), 488-500. doi: http://dx.doi.org/10.1111/j.1741-3729.2012.00707.x

Livingstone, S., \& Helsper, E. (2008). Parental mediation and children's internet use. Journal of Broadcasting \& Electronic Media, 52(4), 581-599. doi: http://dx.doi.org/10.1080/08838150802437396

Malizia, A., \& Bellucci, A. (2012). The artificiality of natural user interfaces. Communications of the ACM, 55(3), 36-38.

doi: http://dx.doi.org/10.1145/2093548.2093563

Manovich, L. (2012). Uue meedia keel. Tallinn: Eesti Kunstiakadeemia.

Mukherji, P., \& Albon, D. (2010). Research methods in early childhood. An introductory guide. London etc.: SAGE Publications.

Nikken, P., \& Jansz, J. (2006). Parental mediation of children's videogame playing: A comparison of the reports by parents and children. Learning, Media and Technology, 31(2), 181-202. doi: http://dx.doi.org/10.1080/17439880600756803

Nikken, P., \& Jansz, J. (2014). Parental mediation of young children's internet use. Retrieved from http://www.lse.ac.uk/media@lse/research/EUKidsOnline/Conference\%202011/Nikken.pdf.

O'Connor, J. (2014). The Technobabies project 2014: How do your babies and toddlers use touchscreens? Retrieved from http://blogs.bcu.ac.uk/views/2014/01/27/thetechnobabies-project-how-do-your-babies-and-toddlers-use-touchscreens/.

Richert, R. A., Robb, M. B., \& Smith, E. I. (2011). Media as social partners: The social nature of young children's learning from screen media. Child Development, 82(1), 82-95. doi: http://dx.doi.org/10.1111/j.1467-8624.2010.01542.x

Rideout, V. (2013). Zero to eight: Children's media use in America 2013. Retrieved from https://www.commonsensemedia.org/file/zero-to-eight-2013pdf-0/download.

Rideout, V. J., \& Hamel, V. (2006). The media family: Electronic media in the lives of infants, toddlers, preschoolers and their parents. The Henry J. Kaiser Family Foundation Report. Retrieved from https://kaiserfamilyfoundation.files.wordpress.com/2013/01/7500.pdf.

Schmitt, K. L., Anderson, D. R., \& Collins, P. A. (1999). Form and content: Looking at visual features of television. Developmental Psychology, 35(4), 1156-1167. doi: http://dx.doi.org/10.1037/0012-1649.35.4.1156

Segal, A. (2011). Do gestural interfaces promote thinking? Embodied interaction: Congruent gestures and direct-touch promote performance in math (Doctoral dissertation). Retrieved from http://academiccommons.columbia.edu/item/ac: 132260.

Simcock, G., \& DeLoache, J. (2006). Get the picture? The effects of iconicity on toddlers' reenactment from picture books. Developmental Psychology, 42(6), 13521357. doi: http://dx.doi.org/10.1037/0012-1649.42.6.1352

Sims, C. E., \& Colunga, E. (2013). Parent-child screen media co-viewing: Influences on toddlers' word learning and retention. In M. Knauff, M. Pauen, N. Sebanz, \& I. Wachsmuth (Eds.), Proceedings of the 35th Annual Conference of the Cognitive Science Society (pp. 1324-1329). Austin, TX: Cognitive Science Society. Retrieved from http://psych.colorado.edu/ holtpatr/Pubs/SimsColungaCogSci2013.pdf. 
Suoninen, A. (2013). Children's media barometer 2013: Media uses of 0-8 year-old children and changes in media uses since 2010. Helsinki: Finnish Youth Research Network. Retrieved from http://www.nuorisotutkimusseura.fi/julkaisuja/childrens_media_barometer_2013.pdf.

Sweetser, P., Johnson, D., Ozdowska, A., \& Wyeth, P. (2012). Active versus passive screen time for young children. Australasian Journal of Early Childhood, 37(4), 94-98.

Zack, E., Barr, R., Gerhardstein, P., Dickerson, K., \& Meltzoff, A. N. (2009). Infant imitation from television using novel touch screen technology. British Journal of Developmental Psychology, 27(1), 13-26. doi: http://dx.doi.org/10.1348/026151008X334700

TNS Emor (2014). Nutiseadmete kasutajate turvateadlikkuse ja turvalise käitumise uuring. Uuringuaruanne 2014. Külastatud aadressil http://www.vaatamaailma. ee/wp-content/uploads/veeb-Nutiseadmete-kasutajate-turvateadlikkuse-ja-turvalise-k\%C3\%A4itumise-uuring_ARUANNE-2014.pdf.

Vinter, K. (2013). Digitaalse ekraanimeedia tarbimine 5-7-aastaste laste seas ja selle sotsiaalne vahendamine Eestis. Pedagoogiline vaatekoht (doktoritöö). Külastatud aadressil http://e-ait.tlulib.ee/318/1/vinter_kristi.pdf. 


\title{
Parents' opinions on parental mediation strategies used to instruct toddlers
}

\author{
Elyna Nevski ${ }^{a}{ }^{1}$, Kristi Vinter ${ }^{\mathbf{a}}$ \\ a Tallinn University, Institute of Education Sciences
}

\begin{abstract}
Summary
Children's use of touch-screen devices begins in infancy, and by the age of one, children are active media users. There is little clear guidance as to how very young children can learn from touch screens and what should be the role of parental assistance. On the other hand, children's use of technology is affected by parental beliefs and that is why it is important to focus on infant and toddler studies.

Touch-screen devices have become an unavoidable part of our lives and also part of toddlers' and infants' everyday life. Studies with parents (Holloway et al., 2013; Rideout \& Hamel, 2006; Suoninen, 2013) have shown that children's experiences with screen media start as early as 3 months and that children will become regular digital media users during the first year of their life, using screen media up to 2 hours a day. The media industry maintains that infant-directed video material can provide an opportunity to improve early learning through educational content that focuses on themes such as language, shape, colour, music, reading, and numbers, embedded in an engaging and perceptually salient video format (Courage \& Howe, 2010).

Despite the optimism of media producers there is insufficient empirical evidence as to whether learning from the screen is beneficial or harmful to children. Scientists have different views on this subject. Children's ability to learn from the screen has been linked with the active participation of parents (Sims \& Colunga, 2013) also from a lack of understanding of the symbolic medium: Infants do not know how depicted objects differ from real ones (Richert et al., 2011; Zack et al., 2009). Different studies (Anderson \& Pempek, 2005; Barr, 2013; Zack et al., 2009) reveal that the infants' ability to transfer learning from screen to real-life situations is relatively poor and that is why infants and toddlers learn more from live personal interactions than from screens.
\end{abstract}

1 Institute of Education Sciences, Tallinn University, Narva Road 25, 10120 Tallinn, Estonia; elyna.nevski@tlu.ee 
Today's homes have gone through extensive changes. Personal computers, easy to use operating systems, gaming consoles and the internet have changed the media landscape of homes where $60 \%$ of Estonians are able to use touchable devices according to the Information System Authority's "Touch screen user's security awareness and safe behaviour” research (2014). Touch screen technology and tablet applications designed for young children fit well with early childhood pedagogy and the emergent fine motor development of children in the early childhood age range (Disney et al., 2013). According to Segal (2011), there is the growing evidence that spontaneous gestures affect thought and possibly learning, because embodied interaction with gestural interfaces involves more senses than traditional (mouse-based) interfaces and includes direct touch and physical movement, which helps retain the knowledge that is being acquired.

Livingstone and Helsper (2008) pointed out three types of parental mediation: active mediation (talking about media content while the child is engaging with the medium), restrictive mediation (setting rules that restrict use of the medium) and co-using/co-viewing (parent remains present while the child is engaged with the medium). Nikken and Jansz (2006) reported similar strategies. Nikken and Jansz (2014) added new types of mediationsupervising (supervising the child from nearby, allowing the child his or her freedom on the computer). Kalmus and Roosalu (2011) composed two extra indices of parental mediation: monitoring mediation (checking the computer later, to see which sites the child visited) and technical restrictions/solutions (filtering software; monitoring software). Parental mediation (interactions that parents have with children about their media use) is divided into six main types but three of them (active mediation, restrictive mediation and co-viewing/using) are the most common. According to this analysis, parents develop different views on monitoring children's online activities as their child gets older.

The aim of this study was to examine Estonian parents' opinions about the necessity of touch screen devices for infants and toddlers, including parental involvement during the child screen-play.

The target group consisted of children 0-3 years of age. A web based questionnaire was sent to pre-school directors. Out of 400 responses $50.7 \%$ per cent applied to girls and $49.3 \%$ per cent to boys. 91.5 per cent of the respondents were either a mother or some other female guardian and 8.5 per cent of them either a father or some other male guardian of a child.

The results of the study lead to the conclusion that parents let their children use touch screens because they saw it as educationally beneficial. 
For those parents, tablets have a place in the development and learning in the home environment. Parents also use tablets as a babysitter to keep their children entertained. Equally, there are parents who do not allow their children to use touch screens at all. Some parents perceived a health risk to their children's eyesight and also the possible adverse effects to parent-child communication.

Young children watch audio-visual programmes, short clips of programmes and videos through YouTube; they mainly use a mobile phone or tablet computers for this purpose. Many parents of the youngest children need information about parental involvement i.e. how to supervise a child's use of digital devices. Parents are very interested in obtaining pedagogical advice, especially as regards educational and age-appropriate content, suggestions for managing children's tablets and advice as how to keep children safe online.

Some strategies indicated active and restrictive involvement, supervision and technical restrictions but further study is needed to investigate how parental involvement occurs in the age-group of two and a half to three year old children.

Keywords: infant, toddler, video-deficit, touch-screens, parental involvement 